\title{
SOJA M-8527 RR Consorciada com BRAQuiáRia Piatã em Diferentes Densidades E ÉPOCAS DE SEMEaduRA ${ }^{1}$
}

\author{
M-SOY 8527 RR Intercropped with Brachiaria Piatã at Different Densities and Sowing Periods
}

\author{
SARAIVA, A.S. ${ }^{2}$, DORNELAS, B.F. ${ }^{2}$, SILVA, J.I.C. ${ }^{2}$, ERASMO, E.A.L. ${ }^{2}$, DORNELAS, D.F. ${ }^{2}$, \\ MATA, J.F. ${ }^{3}$ e SARMENTO, R.A. ${ }^{2}$
}

\begin{abstract}
RESUMO - O cultivo consorciado de culturas para grãos e forrageiras gramíneas é uma das práticas de integração lavoura-pecuária com elevado potencial para maximizar o sistema produtivo. Este trabalho teve o objetivo de avaliar a influência de densidades e épocas de semeadura de Brachiaria brizantha cv. BRS Piatã na produtividade do cultivar de soja M-8527 RR semeado em consórcio. O delineamento experimental foi em blocos casualizados, em esquema fatorial de 2 × 5 (duas épocas de semeadura de B. brizantha: 20 e 30 dias após a emergência da soja; e cinco densidades de semeadura da braquiária: 0, 3, 6, 9 e $12 \mathrm{~kg}$ de semente ha-1), com quatro repetições. Os seguintes parâmetros foram avaliados nas plantas de soja: altura, massa seca da parte aérea e produtividade de grãos. As variáveis avaliadas foram influenciadas pelas densidades e pelas épocas de semeadura de $B$. brizantha. Independentemente da época de semeadura da braquiária, todas as densidades a partir de $3 \mathrm{~kg} \mathrm{ha}^{-1}$ promoveram redução na produtividade da soja; contudo, ela foi superior a $5 \%$ somente na densidade de $12 \mathrm{~kg} \mathrm{~h}^{-1}$, semeada aos $30 \mathrm{DAE}$, e nas densidades de 9 e $12 \mathrm{~kg} \mathrm{ha}^{-1}$, semeada aos 20 DAE. O efeito competitivo da variedade de soja RR M-8527 foi superior quando Brachiaria brizantha cv. Piatã foi semeada aos 30 dias após a emergência da cultura.
\end{abstract}

Palavras-chave: integração lavoura-pecuária, competição, Brachiaria brizantha, renovação de pastagem.

\begin{abstract}
Intercropping of grains and forage grasses is a common practice in integrated crop-livestock systems for maximizing production. This work aimed to evaluate the influence of different densities and sowing periods of Brachiaria brizantha BRS Piatã on the yield of the cultivar M-8527 RR sown in intercropping. The experimental design was a randomized block in a $(2 \times 5)$ factorial arrangement with four replicates, including two sowing periods of $\boldsymbol{B}$. brizantha (20 and 30 days after emergence of soybean seeds) and five sowing densities of Brachiaria $\left(0,3,6,9\right.$ and $12 \mathrm{~kg} \mathrm{ha}^{-1}$ seed). The following parameters were evaluated for soybean: plant height, shoot dry matter and grain yield. The variables evaluated were influenced by the densities and sowing periods of $\boldsymbol{B}$. brizantha. Regardless of the sowing period of $\boldsymbol{B}$. brizantha, all densities up to $3 \mathrm{~kg} \mathrm{ha}^{-1}$ led to a reduction in soybean yield. However, yield was higher than $5 \%$ only at the density of $12 \mathrm{~kg} \mathrm{ha}^{-1}$ sown at $30 \mathrm{DAE}$, as well as at 9 and $12 \mathrm{~kg} \mathrm{ha}^{-1}$ sown at $20 \mathrm{DAE}$. The competitive effect of soybean, cultivar RR M- 8527 was higher when B. brizantha cv. Piatã was sown 30 days after crop emergence.
\end{abstract}

Keywords: integrated crop-livestock systems, competition, Brachiaria brizantha, pasture renewal.

1 Recebido para publicação em 25.2.2014 e aprovado em 7.5.2014.

2 Universidade Federal do Tocantins, Gurupi-TO, Brasil, <althierissaraiva@yahoo.com>; ${ }^{3}$ Universidade Estadual de Minas Gerais, Frutal-MG, Brasil. 


\section{INTRODUÇÃO}

Na safra 2013/2014, a área cultivada com as principais culturas no Brasil correspondeu a 55,39 milhões de hectares. Nesse cenário, a área cultivada com a cultura da soja equivaleu a 29.556.000 ha, com estimativa de produção de 90.331 .400 toneladas. Na região Norte, a área plantada com essa cultura na safra 2013/2014 equivaleu a 1.974,0 ha, sendo o Estado do Tocantins o maior representante, com área plantada correspondente a 897.600 ha e estimativa de produção de 3.018.900 toneladas, com produtividade estimada de $3.363 \mathrm{~kg} \mathrm{ha}^{-1}$ (CONAB, 2014).

Por outro lado, o País possui cerca de 30 milhões de hectares de áreas de pastagens em algum estágio de degradação, com baixíssima produtividade para o alimento animal. O uso correto de tecnologias e de boas práticas agropecuárias torna possivel reinseri-los no processo produtivo (Brasil, 2013).

Diante dessa realidade, uma das alternativas propostas para a recuperação dessas áreas tem sido a utilização de culturas anuais em cultivos sequenciais ou simultâneos, como sistemas de produção agrícola (Silva et al., 2005).

A prática da integração lavoura-pecuária busca obter beneficios recíprocos, eliminando ou reduzindo as causas de degradação física, química ou biológica do solo, resultantes de cada uma das explorações (Kluthcouski et al., 2000). Além disso, os sistemas de integração lavoura-pecuária podem ser promissores para atender tanto às dificuldades da pecuária, como alternativa de recuperação de pastagens degradadas, como para a agricultura anual e o sistema de plantio direto, visando à produção de palha, melhoria das propriedades do solo e utilização plena de equipamentos, empregos e aumento de renda no campo (Macedo, 2009).

Os principais fatores que determinam a competitividade no consócio entre a forrageira e a cultura estão relacionados, entre outros, à densidade populacional, à época de semeadura e à cultura a ser utilizada. Esse tipo de consórcio é estabelecido anualmente, podendo ser implantado simultaneamente à semeadura da soja ou cerca de 10 a 20 dias após a emergência desta, sem que haja necessidade da aplicação de herbicidas na colheita da soja (Kluthcouski et al., 2000).

Entre os fatores que influenciam a competição entre plantas daninhas e culturas, destacam-se a densidade de plantas, a época e a extensão do período de convivência. Esses fatores são importantes para as tomadas de decisão quanto à utilização de herbicidas (Erasmo et al., 2003).

Silva et al. (2005) afirmam que, para viabilizar o consórcio entre a cultura da soja e a Brachiaria brizantha, é necessário o manejo adequado da forrageira, minimizando a competição com a cultura, permitindo boa produtividade da soja e de biomassa da gramínea. A produção de grãos é o objetivo principal do cultivo de soja; para isso, é imprescindivel o conhecimento de alguns parâmetros determinantes nessa competição, a exemplo da densidade de semeadura da gramínea e do período de semeadura desta.

Kluthcouski et al. (2003) afirmaram que há alto grau de risco no consórcio sem nenhum controle de crescimento da braquiária, sugerindo como alternativas a semeadura da forrageira após a emergência da soja ou a utilização de subdose de herbicida.

Tem-se como hipótese que o ajuste de densidades e épocas de semeadura de espécies forrageiras consorciadas com a cultura da soja pode resultar em menor impacto negativo para a leguminosa e, consequentemente, contribuir para a viabilidade do modelo de produção. Entretanto, o presente trabalho teve como objetivo avaliar a influência de diferentes densidades e épocas de semeadura de $B$. brizantha na produtividade do cultivar de soja M-8527 RR, quando semeado em consórcio.

\section{MATERIAL E MÉTODOS}

O estudo foi conduzido na estação experimental da Universidade Federal do Tocantins (UFT), Campus Universitário de Gurupi, localizado na região sudoeste do Estado do Tocantins, a $280 \mathrm{~m}$ de altitude e em clima do tipo Aw, segundo classificação climática de Rubel \& Kottek (2010), definido como equatorial e inverno seco. A temperatura média anual é de $29,5{ }^{\circ} \mathrm{C}$, e a precipitação média anual, de $1.804 \mathrm{~mm}$. As condições climáticas 
do período de condução do experimento são descritas na Figura 1.

O solo da área experimental foi classificado como Latossolo Vermelho-Amarelo Distrófico típico, com as seguintes características químicas: $\mathrm{pH} \mathrm{CaCl}{ }_{2}$ : 4,7; Ca: $2,1 \mathrm{cmol}_{\mathrm{c}} \mathrm{dm}^{-3}$; $\mathrm{Mg}: 0,4 \mathrm{cmol}_{\mathrm{c}} \mathrm{dm}^{-3} ; \mathrm{Al}: 0,2 \mathrm{cmol}_{\mathrm{c}} \mathrm{dm}^{-3}$; $\mathrm{Al}+\mathrm{H}: 2,7 \mathrm{cmol}_{\mathrm{c}} \mathrm{dm}^{-3} ; \mathrm{P}$ (mel): 7,1 $\mathrm{mg} \mathrm{dm}^{-3}$; $\mathrm{K}: 51,6 \mathrm{mg} \mathrm{dm}^{-3}$; CTC: $2,8 \mathrm{cmol}_{\mathrm{c}} \mathrm{dm}^{-3}$; V: 49\%; e MO: $1,9 \%$.

O delineamento experimental utilizado foi em blocos casualizados, em esquema fatorial de $(2 \times 5)$ com quatro repetições, correspondendo a duas épocas de semeadura de Brachiaria brizantha cv. BRS Piatã (20 e 30 dias após a emergência - DAE da soja cultivar M-8527 RR) e cinco densidades de semeadura da braquiária $(0,3,6,9$ e $12 \mathrm{~kg}$ de semente ha ${ }^{-1}$ ).

A semeadura da soja foi feita no dia 30 de dezembro 2009 por meio de uma semeadora adubadora modelo Semeato plantio direto SHM 11/13, com espaçamento entre fileiras de $0,40 \mathrm{~m}$ e densidade de 30 plantas por $\mathrm{m}^{2}$. Antecedendo à semeadura, as sementes de soja foram inoculadas com Bradyrhizobium japonicum. Por ocasião da semeadura, foi realizada adubação com $600 \mathrm{~kg} \mathrm{ha}^{-1}$ de 0-20-20, conforme recomendação feita através da análise de solo. A cultura da soja emergiu no dia 3 de janeiro de 2010.

A semeadura da braquiária foi feita aos 20 e 30 DAE da soja, correspondente aos estágios V2 e V5, respectivamente, sendo a $20 \mathrm{~cm}$ de distância da linha da soja e a $3 \mathrm{~cm}$ de profundidade.

Cada unidade experimental constou de uma área de $10 \mathrm{~m}^{2}$ (5 x $\left.2 \mathrm{~m}\right)$, correspondente a cinco fileiras, sendo a área útil para colheita de $4,8 \mathrm{~m}^{2}$, compreendendo as três fileiras centrais.

Para controle de insetos ao longo do desenvolvimento da cultura, foi aplicado o inseticida Tamaron BR (metamidofós $600 \mathrm{~g} \mathrm{~L}^{-1}$ ). O controle das plantas daninhas foi feito com aplicação de $2 \mathrm{~L} \mathrm{ha}^{-1}$ de glifosato (glyphosate $480 \mathrm{~g} \mathrm{~L}^{-1}$ ) antes da semeadura da braquiária.

Para avaliação do crescimento da cultura da soja, foram colhidas, aos 80 dias após a semeadura - DAS, quatro plantas por parcela, em uma área central de $0,133 \mathrm{~m}^{2}(0,333 \mathrm{x}$ $0,40 \mathrm{~m}$ ), nas quais foram determinados: a) a altura de plantas, tomando-se a medida desde o nível do solo até o ápice (com o limbo foliar distendido); b) o diâmetro do caule, por meio de paquímetro digital, a $5 \mathrm{~cm}$ do solo; c) a massa seca das folhas, do caule, dos drenos (vagens e flores); e d) a massa seca da parte

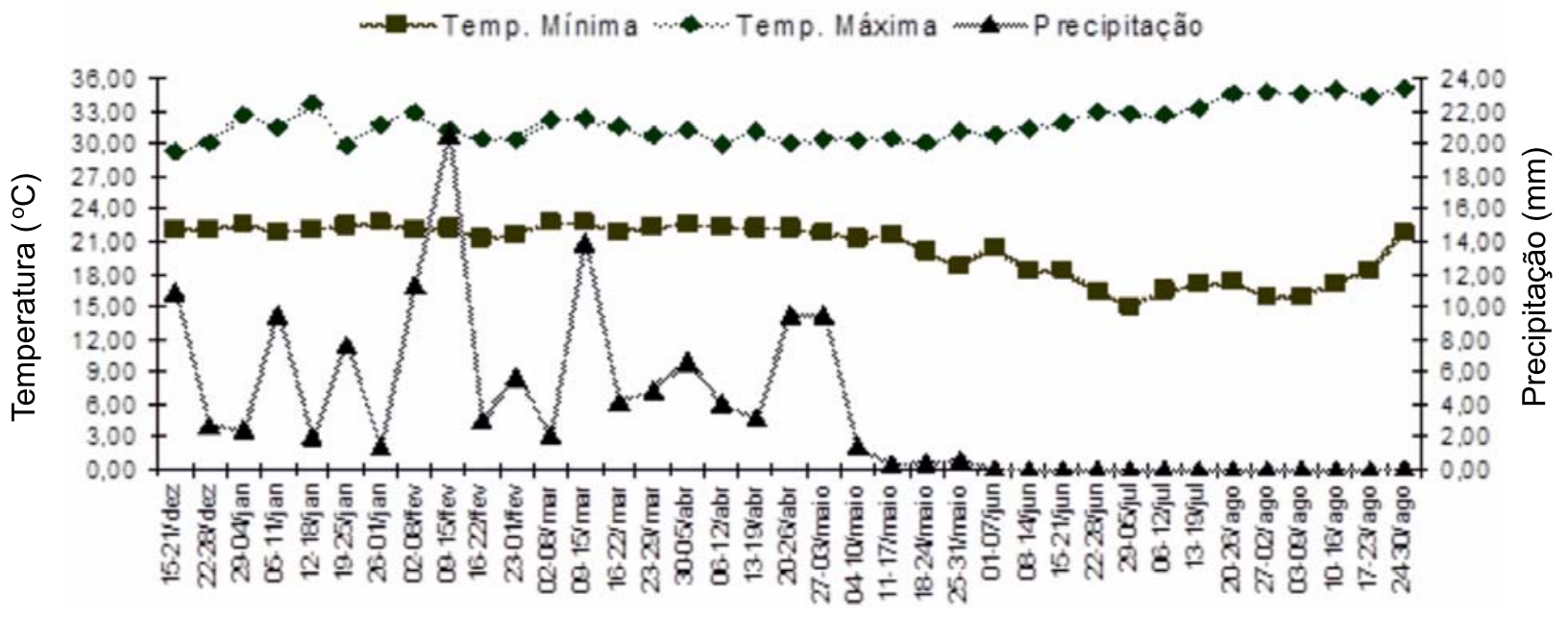

Semana

Fonte: INMET/UFT.

Figura 1 - Temperaturas mínima e máxima e precipitação média durante o ciclo da cultura no ano agrícola 2009/2010. Gurupi-TO. 
aérea (somatório de massa seca de caules, drenos e folhas). Para obtenção da massa seca, esses componentes vegetativos foram colocados em estufa com circulação forçada de ar, à temperatura de $60{ }^{\circ} \mathrm{C}$, até peso constante.

Em se tratando das avaliações relativas à produção, foram coletadas plantas contidas em uma área útil de $2,4 \mathrm{~m}^{2}$ por parcela; determinou-se o peso de 100 grãos (CG) e corrigiuse a umidade para $13 \%$, e a produtividade foi obtida por meio do cálculo do peso dos grãos coletados na área útil da parcela, expresso em kg ha-1.

Os dados foram submetidos à análise de variância pelo teste $\mathrm{F}$, e as médias das características avaliadas, submetidas à análise de regressão. Os ajustes dos modelos foram feitos com base na sua significância e no coeficiente de determinação $\left(\mathrm{R}^{2}\right)$. Os resultados foram submetidos à análise de regressão, utilizando o programa estatístico Microcal Origin 6.1.

\section{RESULTADOS E DISCUSSÃO}

Todas as características avaliadas na soja foram influenciadas pela interação entre as densidades e as épocas de semeadura de B. brizantha.

A altura de plantas de soja em função das densidades de semeadura da braquiária evidenciou uma resposta linear decrescente semelhante para as duas épocas de semeadura da gramínea, sendo significativa $(0,01>p \geq 0,001)$ quando semeada aos $20 \mathrm{DAE}$ e $(0,05>p \geq 0,01)$ na semeadura de $30 \mathrm{DAE}$, com elevados coeficientes de determinação (Figura 2).

A redução na altura de plantas de soja imposta pelo incremento da densidade de semeadura da braquiária, comparada à da testemunha, foi de ordem de 2,7, 6,5, 8,1 e $15,7 \%$, para as densidades de $3,6,9$ e $12 \mathrm{~kg} \mathrm{ha}^{-1}$, respectivamente, para a época de 20 DAE. Para a semeadura realizada 30 DAE, as reduções corresponderam a 1,7, 1,9, 5,9 e $11,2 \%$, para as densidades de 3, 6, 9 e $12 \mathrm{~kg} \mathrm{ha}^{-1}$, respectivamente.

Os maiores decréscimos em altura certamente foram consequência da competição pelos recursos do solo imposta pela braquiária, convivendo mais tempo e em maior densidade com a cultura da soja.

O diâmetro de caule de plantas de soja (Figura 3) apresentou redução proporcional ao aumento da densidade de semeadura da

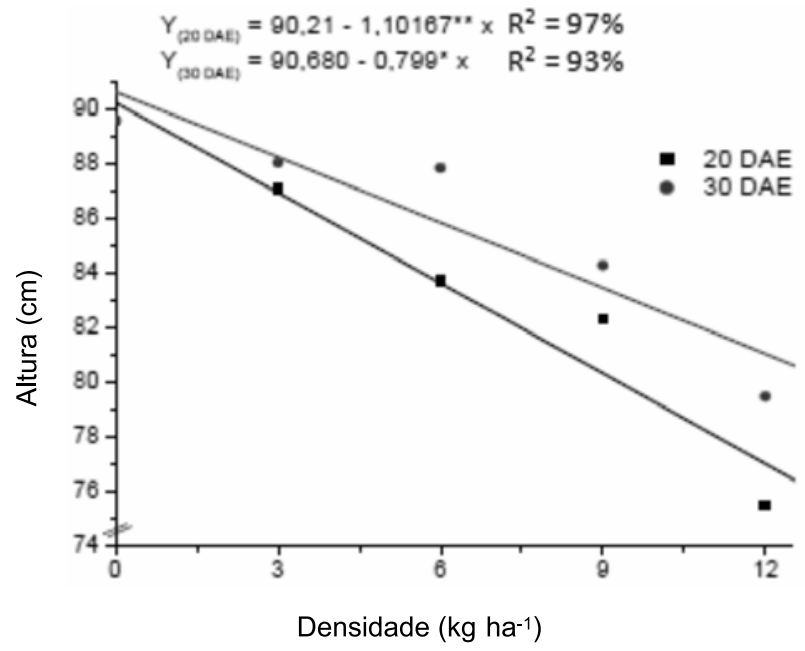

$*(0,05>p \geq 0,01)$ significativo; ** $(0,01>p \geq 0,001)$ altamente significativo.

Figura 2 - Altura de plantas de soja $(\mathrm{cm})$ em função das densidades de semeadura (0, 3, 6, 9 e $12 \mathrm{~kg} \mathrm{ha}^{-1}$ ) de Brachiaria brizantha cv. BRS Piatã, semeada em duas épocas (20 e 30 DAE da soja). Gurupi-TO. Safra 2009/2010.

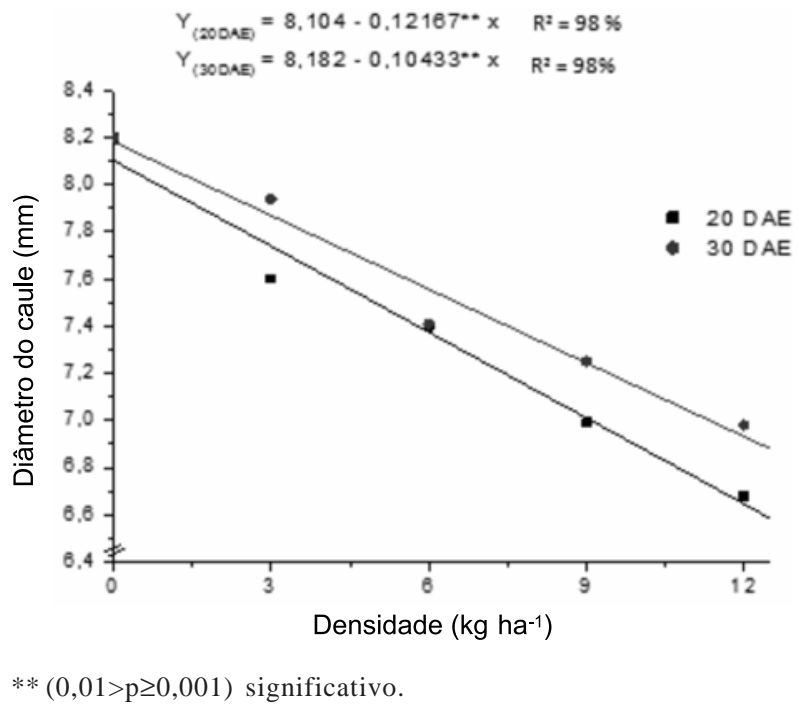

Figura 3 - Diâmetro do caule de plantas de soja em função das densidades de semeadura (0, 3, 6, 9 e $\left.12 \mathrm{~kg} \mathrm{ha}^{-1}\right)$ de Brachiaria brizantha cv. BRS Piatã, semeada em duas épocas (20 e 30 DAE da soja). Gurupi-TO. Safra 2009/2010. 
braquiária nos dois periodos de sua semeadura, ajustando-se a um modelo de regressão linear decrescente altamente significativo $(0,01>p \geq 0,001)$, com elevados coeficientes de determinação.

A redução no diâmetro de caule de plantas de soja imposta pelo incremento da densidade de semeadura da braquiária, comparada à da testemunha, foi da ordem de 7,3, 9,7, 14,7 e $18,5 \%$, para as densidades de 3, 6, 9 e $12 \mathrm{~kg} \mathrm{ha}^{-1}$, respectivamente, na semeadura realizada aos $20 \mathrm{DAE}$, ao passo que aos $30 \mathrm{DAE}$ ela foi de $3,2,9,6,11,6$ e 14,9\%, para as densidades de 3, 6, 9 e $12 \mathrm{~kg} \mathrm{ha}^{-1}$, respectivamente.

A semeadura defasada da braquiária em relação à soja possibilitou a maximização da capacidade competitiva da cultura, exercendo maior sombreamento. De acordo com Cobucci \& Portela (2003), o crescimento da forrageira é lento até os 50 dias após a emergência, exercendo pouca competição com a soja.

Silva et al. (2005) quantificaram os efeitos da interferência de $B$. brizantha, emersa em diferentes épocas em relação à cultura da soja, e constataram que o desenvolvimento da forrageira, quando emersa sete dias após a soja, foi suprimido pela leguminosa.

A massa seca foliar de plantas de soja, em função das densidades de semeadura de braquiária, evidenciou resposta linear decrescente semelhante para as duas épocas de semeadura da gramínea, o que é constatado pela semelhança do coeficiente de regressão de ambas as equações, o qual foi significativo $(0,01>p \geq 0,001)$, com elevados coeficientes de determinação $\left(R^{2}\right)$ (Figura 4).

O acúmulo de massa seca foliar de plantas de soja nas duas épocas de semeadura da braquiária foi maior à medida que se reduziu a densidade de semeadura (Figura 4).

$\mathrm{O}$ acúmulo de massa seca foliar de plantas de soja correspondeu a $466 \mathrm{~kg} \mathrm{ha}^{-1}$, quando solteira, e 405, 386, 353 e $343 \mathrm{~kg} \mathrm{ha}^{-1}$, quando consorciada com $B$. brizantha nas densidades de semeadura de 3, 6, 9 e $12 \mathrm{~kg} \mathrm{ha}^{-1}$, respectivamente, aos 20 DAE da soja. Para essas mesmas densidades, porém com a data de semeadura da braquiária aos $30 \mathrm{DAE}$, os valores corresponderam a 446, 435, 367 e $350 \mathrm{~kg} \mathrm{ha}^{-1}$, respectivamente.

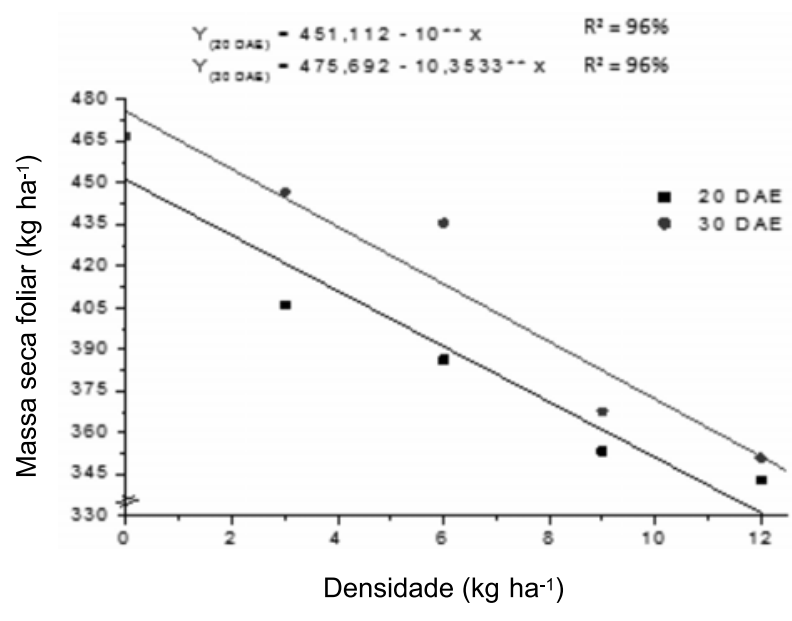

** $(0,01>\mathrm{p} \geq 0,001)$ altamente significativo.

Figura 4 - Massa seca foliar de plantas de soja $\left(\mathrm{kg} \mathrm{ha}^{-1}\right)$ em função das densidades de semeadura (0, 3, 6, 9 e $\left.12 \mathrm{~kg} \mathrm{ha}^{-1}\right)$ de Brachiaria brizantha cv. BRS Piatã, semeada em duas épocas (20 e 30 DAE da soja). Gurupi-TO. Safra 2009/ 2010.

O acúmulo de massa seca foliar de plantas de soja foi sempre maior nos tratamentos em que a semeadura da braquiária foi mais tardia e em menores densidades, expressando maior capacidade competitiva da cultura nessas condições.

A massa seca de flores e vagens de soja, em função das densidades de semeadura da braquiária, evidenciou resposta linear decrescente semelhante para as duas épocas de semeadura da gramínea, o que é constatado pela semelhança do coeficiente de regressão de ambas as equações, o qual foi significativo $(0,01>p \geq 0,001)$, com elevados coeficientes de determinação $\left(\mathrm{R}^{2}\right)$ (Figura 5).

$\mathrm{O}$ acúmulo de massa seca de flores e vagens de plantas de soja, nas duas épocas de semeadura da braquiária, foi maior à medida que se reduziu a densidade de semeadura da graminea.

Valores finais de acúmulo de massa seca do dreno de plantas de soja corresponderam a $496 \mathrm{~kg} \mathrm{ha}^{-1}$, quando solteira, e 458, 393, 373 e $356 \mathrm{~kg} \mathrm{ha}^{-1}$, quando consorciada com $B$. brizantha nas densidades de semeadura de 3, 6, 9 e $12 \mathrm{~kg} \mathrm{ha}^{-1}$, aos 20 DAE da soja. Já para a semeadura realizada aos $30 \mathrm{DAE}$, foram registrados acúmulos de 464, 378, 369 e $331 \mathrm{~kg} \mathrm{ha}^{-1}$, respectivamente. 


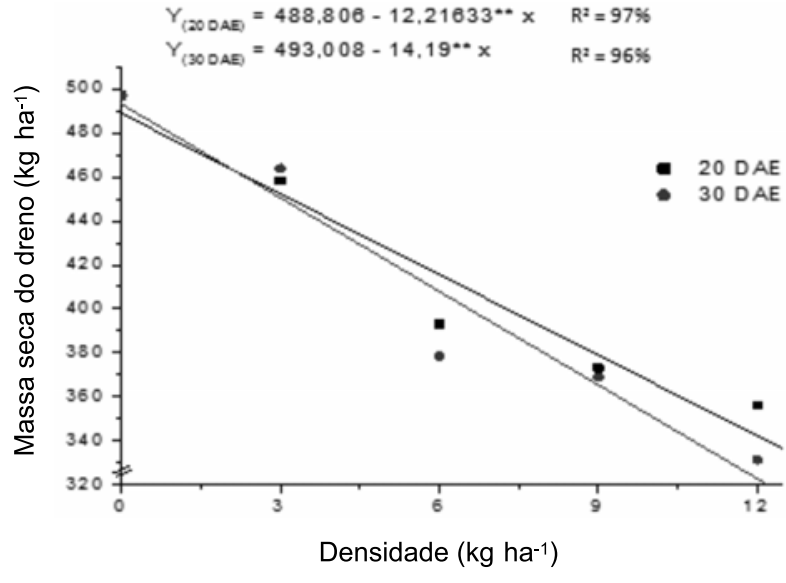

** $(0,01>\mathrm{p} \geq 0,001)$ altamente significativo.

Figura 5 - Massa seca do dreno (flores e vagens) de plantas de soja ( $\left.\mathrm{kg} \mathrm{ha}^{-1}\right)$ em função das densidades de semeadura ( 0,3 , 6, 9 e $12 \mathrm{~kg} \mathrm{ha}^{-1}$ ) de Brachiaria brizantha cv. BRS Piatã, semeada em duas épocas (20 e 30 DAE da soja). GurupiTO. Safra 2009/2010.

$\mathrm{O}$ incremento na massa seca caulinar de plantas de soja nas duas épocas de semeadura da braquiária foi maior à medida que se reduziu a densidade de semeadura (Figura 6).

Valores finais de acúmulo de massa seca caulinar de plantas de soja corresponderam a $1.060 \mathrm{~kg} \mathrm{ha}^{-1}$, quando solteira, e 948, 833, 803 e $744 \mathrm{~kg} \mathrm{ha}^{-1}$, quando consorciada com $B$. brizantha nas densidades de semeadura de 3, 6, 9 e $12 \mathrm{~kg} \mathrm{ha}^{-1}$, respectivamente, aos 20 DAE da soja. Para essas mesmas densidades, porém com semeadura da braquiária realizada aos $30 \mathrm{DAE}$, foram registrados acúmulos de 999, 944, 860 e $790 \mathrm{~kg} \mathrm{ha}^{-1}$, respectivamente.

O acúmulo de massa seca de caules de plantas de soja foi maior na semeadura mais tardia da braquiária e em menores densidades, expressando maior capacidade competitiva da cultura nessas condições.

A redução da massa seca da parte aérea de plantas de soja nas duas épocas de semeadura da braquiária foi crescente com a elevação da densidade de semeadura da graminea (Figura 7).

Valores finais de acúmulo de massa seca da parte aérea de plantas de soja corresponderam a $2.064 \mathrm{~kg} \mathrm{ha}^{-1}$, quando solteira, e $1.812 ; 1.613 ; 1.530$ e $1.460 \mathrm{~kg} \mathrm{ha}^{-1}$, quando consorciada com $B$. brizantha nas densidades de semeadura de $3,6,9$ e $12 \mathrm{~kg} \mathrm{ha}^{-1}$, respectivamente, aos 20 DAE da soja. Para essas

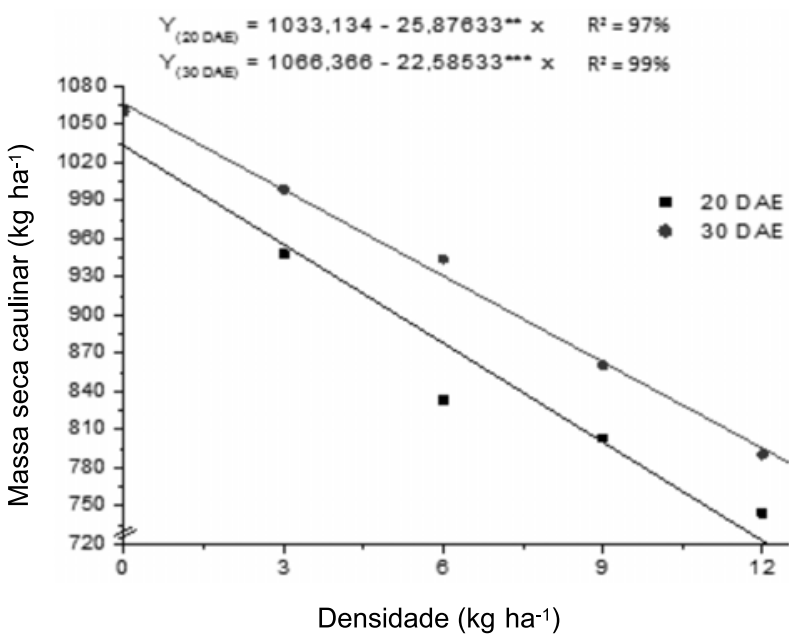

$* *(0,01>\mathrm{p} \geq 0,001)$ altamente significativo; $* * *(\mathrm{p}<0,001)$ altamente significativo.

Figura 6 - Massa seca caulinar de plantas de soja $\left(\mathrm{kg} \mathrm{ha}^{-1}\right)$ em função das densidades de semeadura (0, 3, 6, 9 e $\left.12 \mathrm{~kg} \mathrm{ha}^{-1}\right)$ de Brachiaria brizantha cv. BRS Piatã, semeada em duas épocas (20 e 30 DAE da soja). Gurupi-TO. Safra 2009/ 2010.

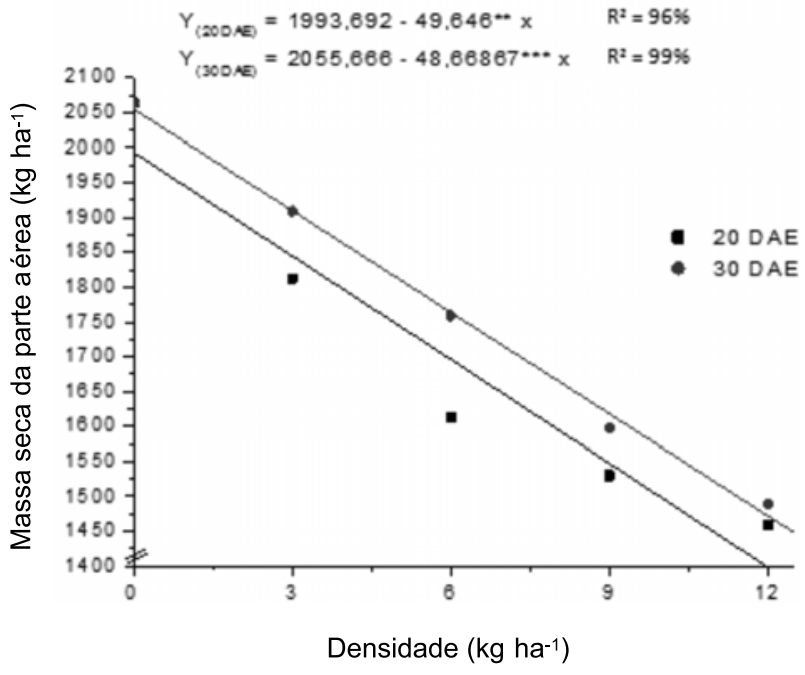

** $(0,01>\mathrm{p} \geq 0,001)$ altamente significativo; $\quad * * *(\mathrm{p}<0,001)$ altamente significativo.

Figura 7 - Massa seca da parte aérea de plantas de soja $\left(\mathrm{kg} \mathrm{ha}^{-1}\right)$ em função das densidades de semeadura (0, 3, 6, 9 e $\left.12 \mathrm{~kg} \mathrm{ha}^{-1}\right)$ de Brachiaria brizantha cv. BRS Piatã, semeada em duas épocas (20 e 30 DAE da soja). Gurupi-TO. Safra 2009/ 2010. 
mesmas densidades, porém com a semeadura da braquiária realizada aos $30 \mathrm{DAE}$, foram registrados acúmulos de $1.909,1.758,1.597 \mathrm{e}$ $1.490 \mathrm{~kg} \mathrm{ha}^{-1}$, respectivamente.

O acúmulo de massa seca da parte aérea de plantas de soja foi sempre maior na semeadura mais tardia da braquiária e em menores densidades (Figura 7), expressando maior capacidade competitiva da cultura nessas condições.

Observou-se decréscimo no peso de 100 grãos de soja com o aumento da densidade de semeadura de $B$. brizantha nas duas épocas em que esta foi semeada, que evidenciou resposta linear decrescente significativa, com elevados coeficientes de determinação (Figura 8).

Constatou-se que o incremento da densidade da braquiária influenciou no peso de 100 grãos quando ela foi semeada aos 20 e $30 \mathrm{DAE}$ da soja. A maior influência ocorreu nos tratamentos em que a gramínea foi semeada aos 20 DAE.

Ao analisar o peso de mil grãos, Silva et al. (2008), avaliando os efeitos da interferência das plantas daninhas sobre os componentes de produção da cultura da soja (cv BRS 243 RR), observaram redução de até 21 e $24 \%$ em áreas de média e alta infestação, respectivamente.

A produtividade da soja decresceu no período de maior convivência com a gramínea e com o aumento das densidades de sementes de $B$. brizantha utilizadas. Os dados se ajustaram a um modelo de regressão linear decrescente, significativo $(\mathrm{p}<0,001)$, quando semeada aos $20 \mathrm{DAE}$, e significativo $(0,05>\mathrm{p} \geq 0,01)$ na semeadura de $30 \mathrm{DAE}$, com elevados coeficientes de determinação $\left(R^{2}\right)$ (Figura 9).

Quando se compararam as produtividades da cultura da soja correspondentes às densidades de consórcio com aquela alcançada crescendo sem a presença da gramínea, verificaram-se decréscimos de 1,88 (0,08\%), 32,81 (1,33\%), 37,50 (1,53\%) e 159,38 (6,50\%) $\mathrm{kg} \mathrm{ha}^{-1}$, relativos às densidades de $3,6,9$ e $12 \mathrm{~kg} \mathrm{ha}^{-1}$, respectivamente, para a época de semeadura de 30 DAE. Quando a semeadura da braquiária foi feita aos $20 \mathrm{DAE}$, essas reduções foram maiores, correspondendo a 37, 5 (1,53\%), 75,0 $(3,06 \%), 150,0(6,12 \%)$ e $192,19(7,84 \%) \mathrm{kg} \mathrm{ha}^{-1}$, respectivamente (Figura 9).

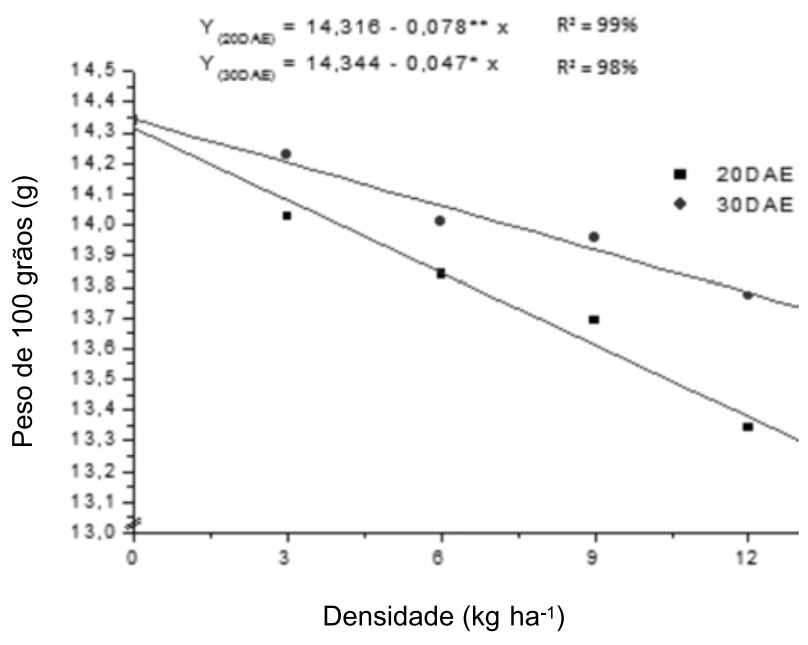

$*(0,05>\mathrm{p} \geq 0,01)$ significativo; $* *(0,01>\mathrm{p} \geq 0,001)$ altamente significativo.

Figura 8 - Peso de 100 grãos de soja (g) em função das densidades de semeadura (0, 3, 6, 9 e $\left.12 \mathrm{~kg} \mathrm{ha}^{-1}\right)$ de Brachiaria brizantha cv. BRS Piatã, semeada em duas épocas (20 e 30 DAE da soja). Gurupi-TO. Safra 2009/2010.

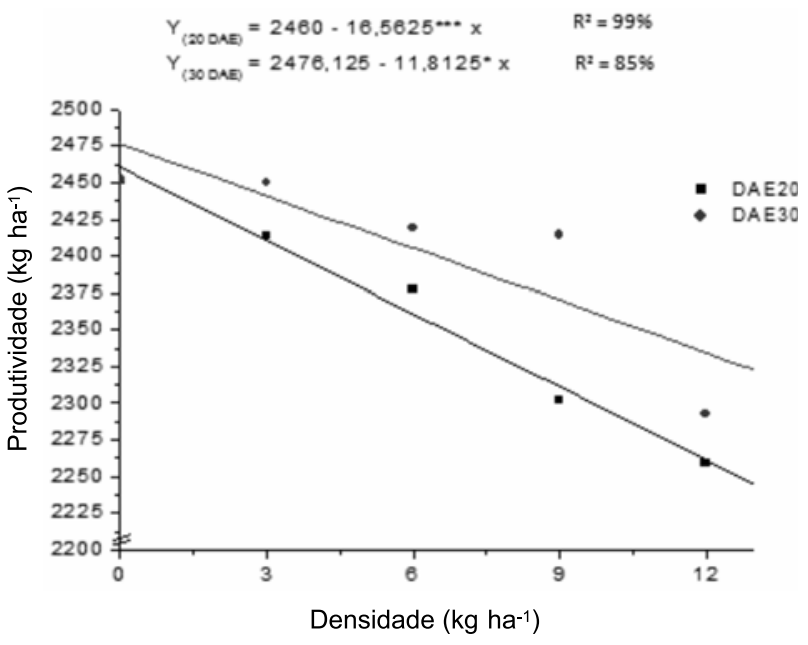

$*(0,05>\mathrm{p} \geq 0,01) \quad$ significativo; $\quad * * *(\mathrm{p}<0,001) \quad$ altamente significativo.

Figura 9 - Produtividade da cultura da soja $\left(\mathrm{kg} \mathrm{ha}^{-1}\right)$ em função das densidades de semeadura (0, 3, 6, 9 e $\left.12 \mathrm{~kg} \mathrm{ha}^{-1}\right)$ de Brachiaria brizantha cv. BRS Piatã, semeada em duas épocas (20 e 30 DAE da soja). Gurupi-TO. Safra 2009/2010.

Rizzardi et al. (2003) avaliaram as perdas de rendimento de grãos de soja provocadas por interferência de picão-preto e guanxuma e verificaram que o aumento nas densidades dessas plantas causou perdas de 58 e 14\%, respectivamente. Kluthcouski et al. (2000) 
observaram reduções no rendimento de grãos, que variaram de 21 a 39\% na cultura da soja consorciada com braquiária, em vários experimentos realizados em GO, BA e MT.

Ao quantificar os efeitos da interferência de $B$. brizantha, emersa em diferentes épocas em relação à cultura da soja, Silva et al. (2005) observaram que nenhum tratamento avaliado igualou-se ao da soja em monocultivo quanto à produção de grãos por planta, verificando-se redução de rendimento de aproximadamente $97,96,91,80,34,27$ e $15 \%$ quando $B$. brizantha emergiu aos $-21,-14,-7,0,7,14$ e 21 dias em relação à soja, respectivamente.

Ao analisar os resultados encontrados, devem-se considerar os padrões de crescimento e exigências das espécies envolvidas, destacando-se que a soja é uma planta $\mathrm{C}_{3}$, e a braquiária, $\mathrm{C}_{4}$, assim como a proporção entre as espécies consorciadas, que está relacionada à densidade destas, e o período de início dessa convivência.

Quando a braquiária foi semeada aos 20 e 30 dias após a emergência da soja, esta cultura encontrava-se nos estádios V3 e V5, respectivamente. Dessa forma, as plantas de braquiária encontraram condição estressante em relação à disponibilidade de luz, principalmente aos 30 DAE. Esses resultados corroboram aqueles obtidos por Mata et al. (2011), os quais observaram que Brachiaria brizantha em consórcio com a cultura da soja apresentou crescimento lento, em especial por possuir metabolismo $\mathrm{C}_{4}$ de fixação do $\mathrm{CO}_{2}$ - característica que a faz exigente por luz.

Foi evidente o efeito competitivo imposto pela gramínea, sobretudo nas maiores densidades e na primeira data de semeadura, explicado pelo maior tempo de convivência e consumo de recursos.

De acordo com Bianchi et al. (2006), os recursos disponíveis abaixo da superficie do solo são mais importantes nas relações de competição do que a radiação solar, durante a fase de crescimento vegetativo das plantas. Segundo Falik et al. (2003), as plantas que crescem isoladas apresentam produtividade superior à daquelas que crescem juntas e na presença de vizinhos: o sistema radicular prolifera mais em número e acumula mais matéria seca nas raízes em direção ao vizinho do que na direção de outras raízes da mesma planta. Esse processo de evitar suas próprias raizes auxilia as plantas a minimizar o desperdício na alocação de carboidratos, de modo a superar a competição com si própria. Dessa maneira, a rapidez de ocupação do espaço, expressa principalmente na formação de raízes, será uma das principais características de sucesso das plantas.

As variáveis avaliadas na cultura da soja foram influenciadas pelas densidades e pelas épocas de semeadura de $B$. brizantha. Independentemente da época de semeadura da braquiária, todas as densidades a partir de $3 \mathrm{~kg} \mathrm{ha}^{-1}$ promoveram redução na produtividade da soja; contudo, ela foi superior a $5 \%$ somente na densidade de $12 \mathrm{~kg} \mathrm{ha}^{-1}$, semeada aos $30 \mathrm{DAE}$, e nas densidades de 9 e $12 \mathrm{~kg} \mathrm{ha}^{-1}$, semeada aos 20 DAE. O efeito competitivo da variedade de soja RR M-8527 foi superior quando $B$. brizantha $\mathrm{cv}$. Piatã foi semeada 30 dias após a emergência da cultura.

\section{AGRADECIMENTOS}

Aos colaboradores Marciane Dotto, Analu Guarnieri, André Amaral, Marília Barcelos, $\mathrm{Dr}^{\mathrm{a}}$. Susana C. Siebeneichler e Dr. Marçal Pedro Neto. Ao Governo do Estado do Tocantins, Secretaria de Ciência e Tecnologia-SECT e Conselho Estadual de Ciência e TecnologiaCECT, pelo apoio financeiro. À Universidade Federal do Tocantins, pelo suporte.

\section{LITERATURA CITADA}

BIANCHI, M. A.; FLECK, N. G.; DILLENBURG, L. R. Partição da competição por recursos do solo e radiação solar entre cultivares de soja e genótipos concorrentes.

Planta Daninha, v. 24, n. 4, p. 629-639, 2006.

COBUCCI, T.; PORTELLA, C. M. O. Manejo de herbicidas no Sistema Santa Fé e na braquiária como fonte de cobertura morta. In: KLUTHCOUSKI, J.; STONE, L. F.; AIDAR, H. (Ed.). Integração lavoura-pecuária. Santo Antonio de Goiás: Embrapa-CNPAF, 2003. p. 569.

CONAB. Acompanhamento da safra brasileira: Grãos, safra 2013/2014, quarto levantamento. v. 1, n. 4, Janeiro, 2014. ISSN 2318-6852

ERASMO, E. A. L. et al. Efeito da densidade e de períodos de convivência de Cyperus esculentus na cultura do arroz irrigado. Planta Daninha, v. 21, n. 3, p.381-386, 2003. 
FALIK, O. et al. Self/non-self discrimination in roots.

J. Ecol., v. 91, n. 4, p. 525-531, 2003.

KLUTHCOUSKI, J. et al. Sistema Santa Fé - Tecnologia Embrapa: integração lavoura pecuária pelo consórcio de culturas anuais com forrageiras, em áreas de lavoura, nos sistemas plantio direto e convencional. Santo Antônio de Goiás: Embrapa Arroz e Feijão, 2000. 28 p. (Circular Técnica, 38).

KLUTHCOUSKI, J.; STONE, L. F.; AIDAR, H. Integração lavoura pecuária. Santo Antônio de Goiás: Embrapa Arroz e Feijão, 2003. 570 p.

MACEDO, M. M. C. Integração lavoura e pecuária: o estado da arte e inovações tecnológicas. R. Bras. Zootec., v. 38, supl. esp, p. 133-146, 2009.

BRASIL. Ministério da Agricultura, Pecuária e Abastecimento. Recuperação de áreas degradadas.

Disponível em: <http://www.agricultura.gov.br/ desenvolvimento-sustentavel/recuperacao-areas-degradadas $>$. Acesso em: 11 mar. 2013.
MATA, J. F. et al. Análise de crescimento da brachiária em diferentes densidades e épocas de semeadura em consórcio com a cultura da soja. R. Bras. Tecnol. Aplicada Ci. Agr., v. 4, n. 3, p. 7-30, 2011.

ORIGIN ${ }^{\circledR}$. Microcal Software, Inc. Version 6.1. 2000.

RIZZARDI, M. A. et al. Perdas de rendimento de grãos de soja causadas por interferência de picão-preto e guanxuma. Ci. Rural, v. 33, n. 4, p. 621-627, 2003.

RUBEL, F.; KOTTEK, M. Observed and projected climate shifts 1901-2100 depicted by world maps of the KöppenGeiger climate classification. Meteorol. Zeitschrift, v. 19, n. 2, p. 135, 2010.

SILVA, A. C. et al. Caracteres morfológicos de soja e braquiária consorciadas sob subdoses de fluazifop-p-butil. Ci. Rural, v. 35, n. 2, p. 277-283, 2005.

SILVA, A. F. et al. Densidades de plantas daninhas e épocas de controle sobre os componentes de produção da soja.

Planta Daninha, v. 26 n. 1, p. 65-71, 2008. 